\title{
RAM investigation of coal-fired thermal power plants: A case study
}

\author{
D. D. Adhikary ${ }^{a^{*}}$, G. K. Bose ${ }^{a}$, S Chattopadhyay ${ }^{b}$, D. Bose ${ }^{c}$ and S. Mitra ${ }^{d}$
}

${ }^{a}$ Department of Mechanical Engineering, Haldia Institute of Technology, Haldia, India

${ }^{b}$ Department of Production Engineering, Haldia Institute of Technology, Haldia, India

${ }^{c}$ Department of Mechanical Engineering, National Institute of Technical Teachers' Training and Research, Kolkata, India

${ }^{d}$ Department of Production Engineering, Jadavpur University, Kolkata, India

\section{A R T I C L E I N F O

A B S T R A C T

Article history:

Received 28 October 2011

Accepted December, 52011

Available online

8 December 2011

Keywords:

RAM investigation

Coal-fired Thermal Power Plant

Critical Subsystem

Preventive Maintenance Interval

Decreasing Failure Rate

Increasing Failure Rate

\begin{abstract}
Continuous generation of electricity of a power plant depends on the higher availability of its components/equipments. Higher availability of the components/equipments is inherently associated with their higher reliability and maintainability. This paper investigates the reliability, availability and maintainability (RAM) characteristics of a $210 \mathrm{MW}$ coal-fired thermal power plant (Unit-2) from a thermal power station in eastern region of India. Critical mechanical subsystems with respect to failure frequency, reliability and maintainability are identified for taking necessary measures for enhancing availability of the power plant and the results are compared with Unit-1 of the same Power Station. Reliability-based preventive maintenance intervals (PMIs) at various reliability levels of the subsystems are estimated also for performing their preventive maintenance (PM). The present paper highlights that in the Unit-2, Economizer (ECO) \& Furnace Wall Tube (FWT) exhibits lower reliability as compared to the other subsystems and Economizer (ECO) \& Baffle Wall Tube (BWT) demands more improvement in maintainability. Further, it has been observed that FSH followed Decreasing Failure Rate (DFR) and Economizer (ECO) is the most critical subsystem for both the plants. RAM analysis is very much effective in finding critical subsystems and deciding their preventive maintenance program for improving availability of the power plant as well as the power supply.
\end{abstract}

\section{Introduction}

With the rapid growth in domestic and commercial market in Indian electricity, consumption is increasing with leaps and bounce. Coal-Fired Thermal Power Plant caters more than $65 \%$ of the required power (Behera \& Dash, 2010). One of the most important requirements of any power plant is to guarantee its higher availability for maximization of power supply. The higher availability of a complex power plant is depending upon higher reliability and maintainability of its components/equipments. The components/equipments of a power plant, however well designed, will not perform satisfactorily unless they are maintained. Hence the general objective of maintenance of the equipments is to make use of the relevant information regarding failures and repairs.

* Corresponding author Tel: +91-9475222059

E-mail: d_dasadhikary@rediffmail.com (D. D. Adhikary)

(C) 2012 Growing Science Ltd. All rights reserved. doi: 10.5267/j.ijiec.2011.12.003 
It is interesting to note that very few studies have been conducted on individual equipments of coalfired thermal power plants. Woo (1980) performed a study on reliability of an experimental fluidizedbed boiler of a coal-fueled plant to determine the major contributors to plant outage in terms of equipment failure and plant management. Arora and Kumar (1993) carried a maintenance planning and management of coal crushing system in the coal-fired thermal power plant. Kaushik and Singh (1994) presented reliability analysis of the feed water system in a thermal power plant. They calculated reliability and availability function $\left(\mathrm{A}_{v}\right)$ and mean time to failure (MTTF) of this system, followed by analysis of the results. Arora et al. (1995) carried a reliability analysis and maintenance planning of coal conveyor system in a thermal power plant. Arora and Kumar (1997) analyzed availability of steam and power generation systems in the thermal power plant. They derived the expressions for steady state availability and the MTBF (mean time between failure), considering constant failure and repair rates for each working unit.

Arora and Kumar (1997) did stochastic analysis and maintenance planning of the ash handling system in the thermal power plant, situated in North India. They analysed behaviour of each working unit and discussed the problems and remedies with appropriate maintenance schedules. Liwei et al. (2005) proposed a new method and algorithm for functional reliability simulation for a steam-turbine's behaviour and established a degeneration model based on the laws of the steam-turbine. Rahman et al. (2010) worked on root cause failure analysis of a division wall superheater tube (super alloy Inconel ${ }^{\circledR} 800$ ) of a coal-fired power station in Kapar Power Station, Malaysia. Purbolaksono et al. (2010) had undergone failure case studies of SA213-T22 steel tubes of the reheater and superheater of boiler using computer simulations.

Therefore it is imperative to investigate the RAM characteristics of all mechanical equipments, for taking necessary measures regarding maximization of power supply. Adhikary et. al. (2010) analyzed the reliability, maintainability and availability characteristics of a coal-fired power plant of $210 \mathrm{MW}$ (Unit-1) from a power station, in eastern region of India. The study finds that ECO \& PSH (Primary Superheater) had more frequency of failure than that of the other subsystems. It has been observed that FSH followed Decreasing Failure Rate (DFR). ECO and PSH are more critical with respect to reliability, whereas PSH and FWT are critical with respect to maintainability. Further PMIs at various reliability levels for the subsystems have been estimated for reducing their failures by PM.

The present paper investigates the RAM characteristics of Unit-2 from the same power station. Although the both plants are from the same power station, the RAM characteristics of their mechanical equipments may not be the same. Therefore, an attempt is made to find out the critical subsystems with respect to failure frequency, reliability and maintainability point of view for adopting measures for enhancing availability of the Unit-2 and the results are compared with that of the Unit-1. Then PMIs of the subsystems are estimated at $75 \%, 80 \% \& 90 \%$ reliability levels for performing their PM. The respective failure and repair data of the power plant due to the failure of mechanical components/equipments are sorted into 10 subsystems for easy estimation of reliability, maintainability and availability. The subsystems are Economizer (ECO), Furnace Wall Tubes (FWT), Baffle Wall Tubes (BWT), Primary Superheater (PSH), Platen Superheater (PLSH), Final Superheater (FSH), Turbine (TUR), Primary Reheater (PRH), Pendent or Final Reheater (FRH) and Condenser $(\mathrm{CON})$. These subsystems are in series from the reliability and maintainability point of view.

The Boiler Feed Pump (BFP) is supported by three pumps connected in parallel and the Coal Mill $(\mathrm{CM})$ is supported by six parallel connected mills. Apart from these there are many auxiliary mechanical systems like air compressor (Instrument type and Plant type), condensate extraction pump, etc. These subsystems are not taken into consideration since their failure has no instant impact on uninterrupted power generation. Furthermore plant failure due to malfunctioning of electrical component like generator is not considered in the present investigation. 


\section{Data collection}

Data collections have been carried out over a long period of time for true failure/repair characterization. In the present study maintenance data is collected from the plant's maintenance logbook records over a period of 12 years, which are sorted and classified for analysis.

\section{Frequency of Failure Analysis}

The frequency of failure analysis of subsystems has been carried out with the help of Pareto Principle (Barabady \& Kumar, 2008; Adhikary et. al., 2010) The Pareto analysis is aimed to identify the "significant few and the insignificant many" subsystems and is shown in the Fig.1.

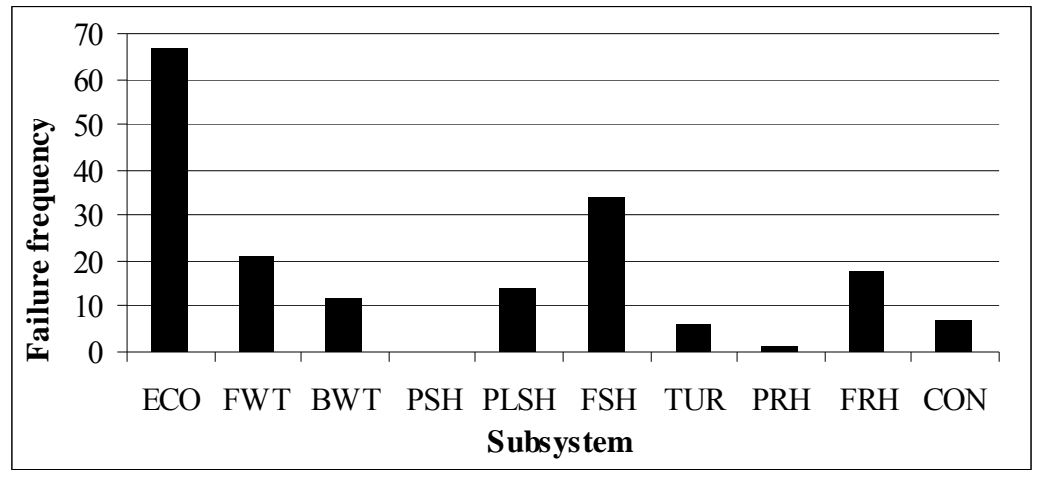

Fig. 1. Failure frequency of the Subsystems

It is observed from Fig. 1 that the subsystems ECO and FSH have more frequency of failure as compared to the other subsystems. The plant failed 101 times due to the failure of these subsystems out of total no of failure 180 during the time period under investigation. Hence $56 \%$ plant failure occurs due to the failure of $20 \%$ of its mechanical subsystems in series. Therefore these subsystems need to be inspected more for maintenance than the other subsystems. Furthermore, PRH and PSH have only one and zero failures respectively during the study period. Therefore they are not considered in the estimation of reliability, maintainability and availability.

\section{Data analysis}

Validity of the assumptions of independent and identical distribution (idd) of Time Between Failure (TBF) and Time To Repair (TTR) data are verified using Trend Test and Serial Correlation Test before fitting to the statistical distributions.

\subsection{Trend Test}

The Trend Test for TBF/TTR data is done graphically by plotting the cumulative frequency of failure/repair against the cumulative TBF/TTR respectively. In case of Trend Test of TBF data, concave upward curve indicates that the system is deteriorating and concave downward curve indicates the system is improving. But in case of TTR data, concave upward curve means that TTR is decreasing and concave downward curve indicates the TTR is increasing. If the curve is approximately a straight line, then the data is identically distributed and free from trends (Kumar \& Kelefsjö, 1992; Rigdon \& Basu, 2000; Barabady, 2005; Adhikary et. al., 2010)

\subsection{Serial Correlation Test}

The Serial Correlation Test can be performed graphically by plotting the $i^{\text {th }}$ TBF/TTR against $(\mathrm{i}-1)^{\text {th }}$ $\mathrm{TBF} / \mathrm{TTR}$ for $\mathrm{i}=1,2 \ldots \mathrm{n}$, where $\mathrm{n}$ is the total number of failures (Kumar \& Kelefsjö, 1992; Rigdon, \& Basu, 2000; Barabady, 2005; Adhikary et. al., 2010). If the points are scattered without any clear pattern, then the data are independent i.e. free from serial correlation; in other words, each 
failure/repair is independent of the preceding or succeeding failure/repair. If the data is dependent or correlated, the points should lie along a line.

The Trend Tests and Serial Correlation Tests are carried out on TBF and TTR data sets of the subsystems. Due to paucity of space, Trend Tests and Serial Correlation Tests plot for TBF data sets of some subsystems are shown in Fig. 2 \& Fig. 3 respectively whereas for TTR data sets of some subsystems are shown in Fig. 4 \& Fig. 5 respectively.

In the test, weak or no absolute trends (Fig. 2. (a), (b), (d)) are found except TBF data of FSH (Fig. 2.(c)). The trend plot curve of FSH exhibits concave downward which indicates improvement in the reliability after high infant mortality at earlier stages.

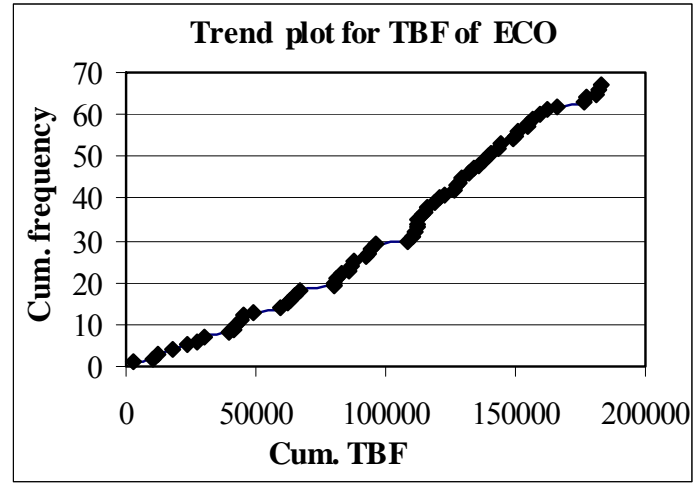

(a)

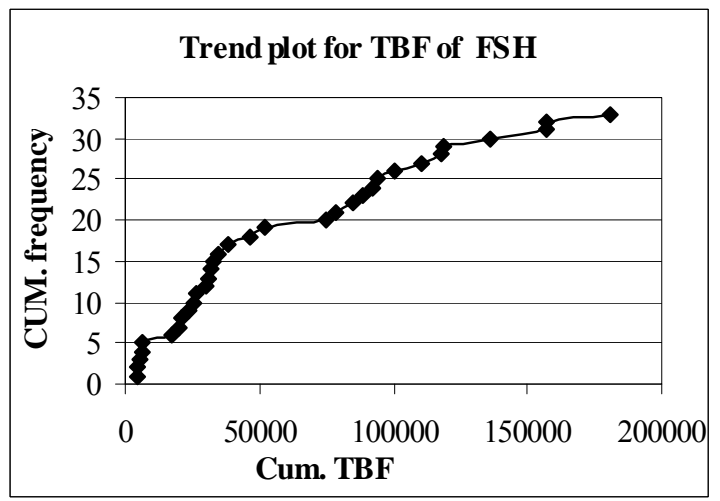

(c)

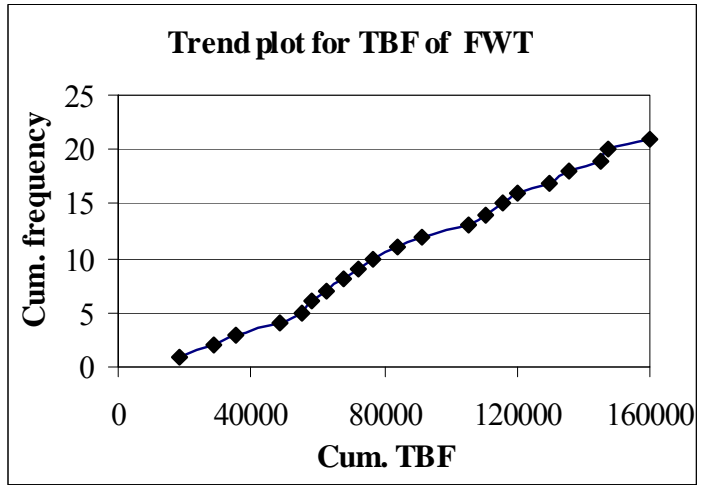

(b)

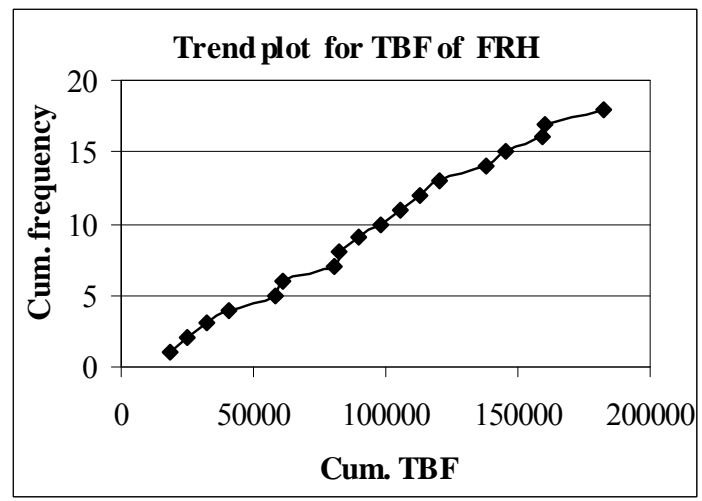

(d)

Fig. 2. Trend Test plot for TBF of the Subsystems

It is observed from the serial correlation plots (Fig. 3) that the data points are randomly scattered without any clear pattern, which indicates that the TBF data sets are independent or free from serial correlation. So the TBF data sets can be assumed to be independent and identically distributed (iid) except FSH.
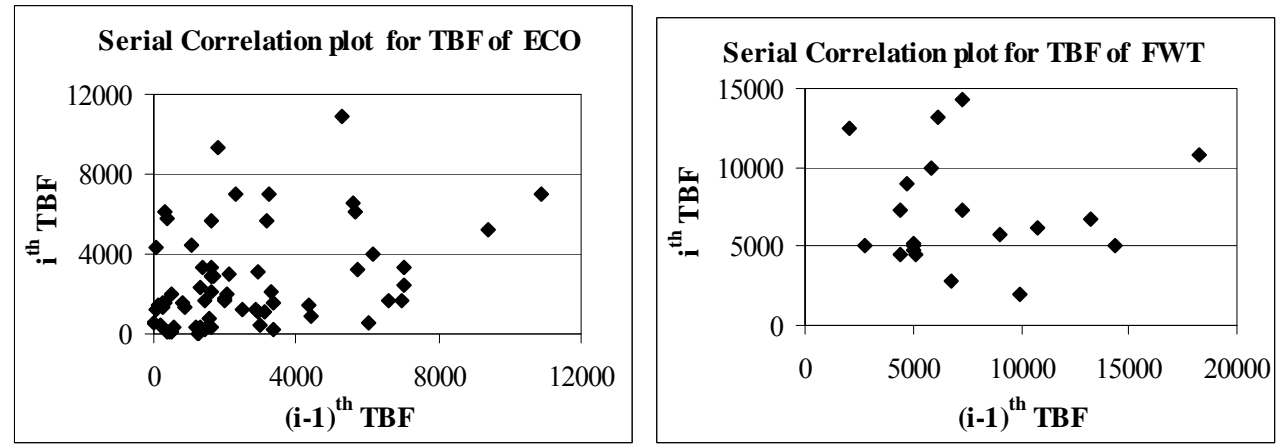

Fig. 3. Serial Correlation test plot for TBF of the Subsystems 
The trend plots for TTR data of the subsystems exhibit approximate straight line (Fig. 4 (b)) except ECO (Fig. 4 (a)). Trend plot curve of ECO shows concave upward, which indicates that the TTR is decreasing.

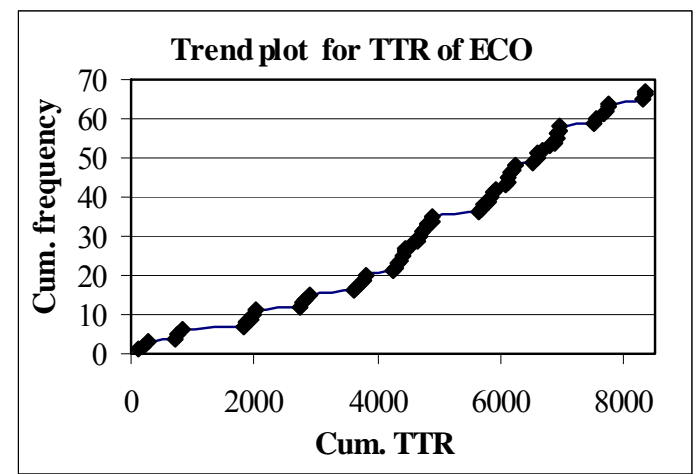

(a)

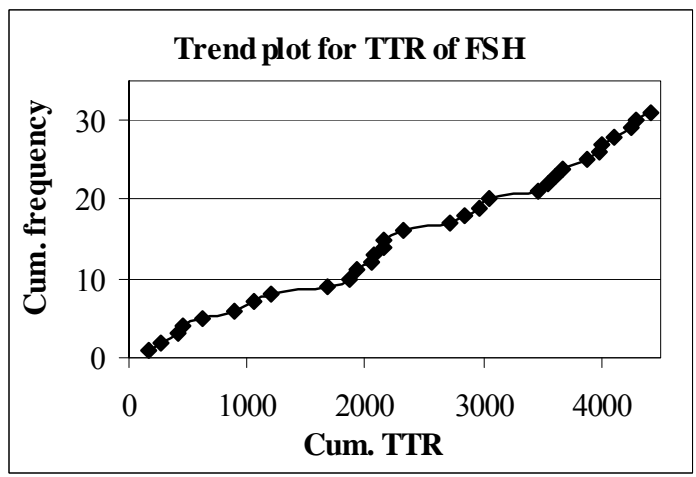

(b)

Fig. 4. Trend Test plot for TTR of the Subsystems

The data points are randomly scattered (Fig. 5 (a), (b)) in the serial correlation test plots for TTR data sets, which indicates that the data sets are independent or free from serial correlation. So the TTR data sets can be assumed to be iid except ECO.

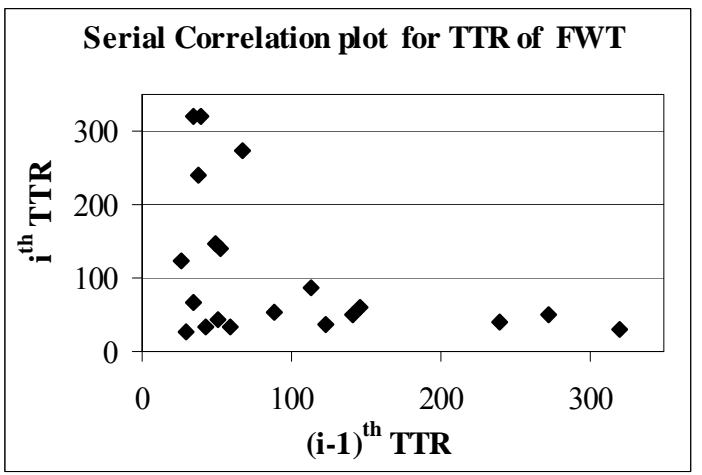

(a)

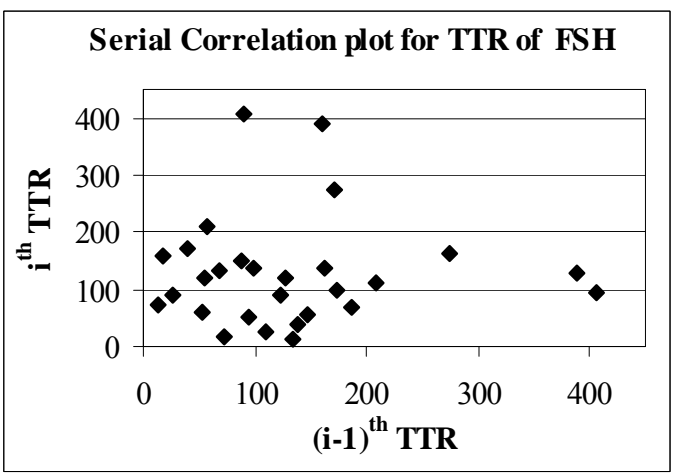

(b)

Fig. 5. Serial correlation test plot for TTR of the Subsystems

\section{Goodness-of-fit Test for iid data and their parameters estimation}

Kolmogorov-Smirnov test is used for goodness-of-fit test of idd data sets using EasyFit5.5 professional software. The parameters for the best fitted statistical distributions are estimated by least-square method. In the Weibull model, the parameters $\beta$ (Shape parameter) and $\theta$ (Scale parameter) can be determined by plotting $\ln \ln \left[1 /\left\{1-F\left(t_{i}\right)\right\}\right]$ against $\ln \left(t_{i}\right)$. The slope and intercept of the least-square fitted straight line to these data pints are the value of $\beta$ and $\beta \ln \theta$ respectively (Ebeling, 2008). Equation of the least-square fitted straight line to the above data points in the plot is given by Eq. (1) (Ebeling, 2008). 
$\ln \ln \left[\frac{1}{1-F\left(t_{i}\right)}\right]=\beta \ln t-\beta \ln \theta$

where $F\left(t_{i}\right)=(i-0.3) /(n+0.4)=$ cumulative percentage of failures or repairs and $t_{i}$ is $i^{\text {th }}$ TBF or TTR.

Similarly in the case of Lognormal distribution, the parameters $s$ (shape parameter) and $t_{\text {med }}$ (location parameter, called median time to failure) are calculated by plotting $z_{i}$ against $\ln \left(t_{i}\right)$. The slope and intercept of the least-square fitted straight line to these data points are the value of ' $1 / \mathrm{s}$ ' and '(1/s) $\ln t_{\text {med }}$ ', respectively (Ebeling, 2008). Equation of the least-square fitted straight line to the above data points in the plot is followed by equation (2) (Ebeling, 2008).

$$
\mathrm{z}=\Phi^{-1}\left[\mathrm{~F}\left(\mathrm{t}_{\mathrm{i}}\right)\right]=(1 / \mathrm{s}) \ln t_{\mathrm{i}}-(1 / \mathrm{s}) \ln t_{\mathrm{med}}
$$

where, $\mathrm{z}$ is standardized normal variate, $\Phi(\mathrm{z})$ is the cumulative distribution function.

Goodness-of-fit test for TBF data set of ECO using Easyfit 5.5 professional software and the parameter estimation by least square method for example are shown in the Fig. 6 \& Fig. 7 respectively.

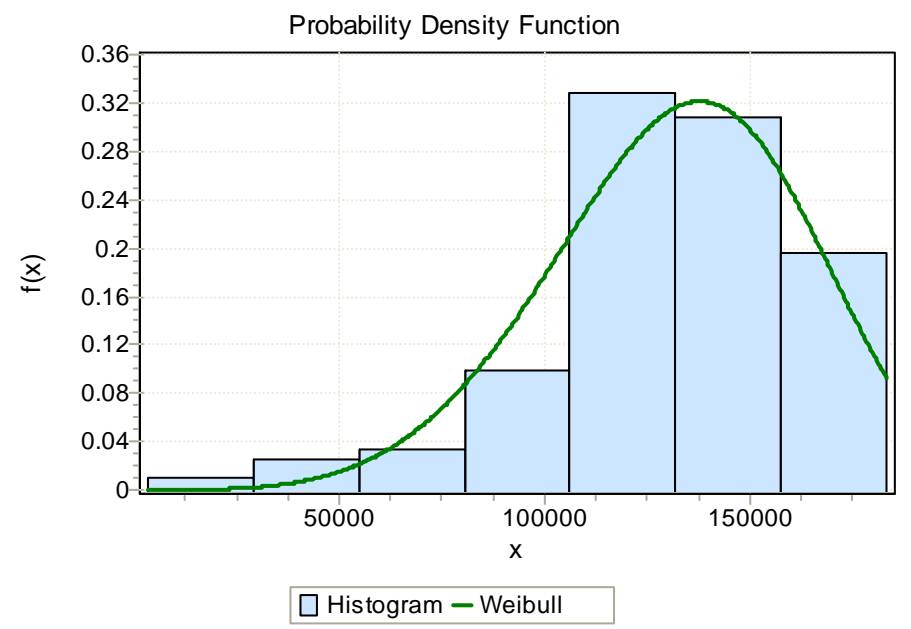

Fig. 6. Histogram showing Goodness-of-fit test for TBF data set of ECO

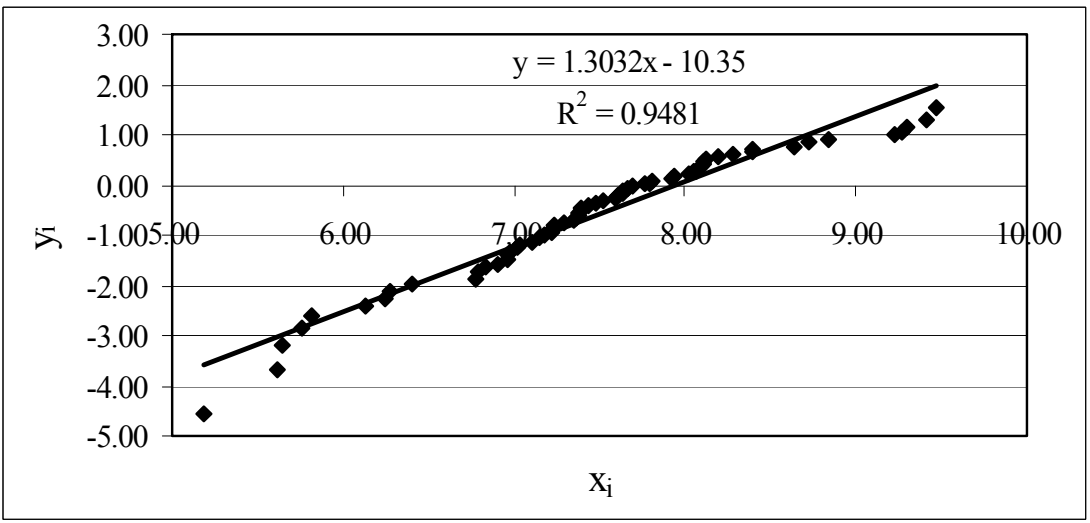

Fig. 7. Least-square fitted plot for data points $\left(x_{i}=\ln \left(t_{i}\right), y_{i}=\ln \ln \left[1 /\left\{1-F\left(t_{i}\right)\right\}\right]\right)$ of ECO 
In the plot, Intercept $=\beta \ln \theta=-10.35$ and Slope $=\beta=1.3032$, Therefore $\theta=2813$

\section{Goodness-of-fit Test for non-idd data and the parameters estimation}

The data with trends are analyzed by Non-Homogeneous Poisson Process (NHPP) (Kumar and Kelefsjö, 1992; Rigdon and Basu, 2000; Barabady, 2005; Adhikary et. al., 2010). In the present study, power law process NHPP model is used for reliability modeling of FSH and maintainability modeling of ECO. The intensity function is given by:

$\lambda(t)=\left(\frac{\beta}{\theta}\right) \cdot\left(\frac{t}{\theta}\right)^{(\beta-1)}$,

where, $\beta$ is shape parameter and $\theta$ is scale parameter. Goodness-of-fit test of non-iid TBF/TTR data sets for power law process are performed graphically by TTT (Total Time on Test) plot. If the plot lies close to the diagonal in the unit square, then the power law process may be an acceptable model (Rigdon and Basu, 2000). The parameters $\beta$ and $\theta$ for the Power Law Process is estimated by Maximum Likelihood Estimation using Eq. (4) \& Eq. (5), respectively (Ebeling, 2008).

$$
\beta=n / \sum_{i=1}^{n} \ln \left(t_{n} / t_{i}\right)
$$

$\theta=\frac{t_{n}}{n^{1 / \beta}}$

TTT plots for TBF data of FSH and TTR data of ECO are shown in the Fig. 8, where, $\mathrm{i}=\mathrm{i}^{\text {th }}$ failure out of total number of failure ' $n$ ', $h\left(t_{i}\right)=$ Total Time on Test to age $t_{i}=n t_{1}+(n-1)\left(t_{2}-t_{1}\right)+\ldots .+(n-$ $\mathrm{i}+1)\left(\mathrm{t}_{\mathrm{i}}-\mathrm{t}_{\mathrm{i}-1}\right), \mathrm{h}\left(\mathrm{t}_{\mathrm{n}}\right)=$ Total Time on Test to age $\mathrm{t}_{\mathrm{n}}$, Scaled $\mathrm{h}\left(\mathrm{t}_{\mathrm{i}}\right)=\mathrm{u}_{\mathrm{i}}=\mathrm{h}\left(\mathrm{t}_{\mathrm{i}}\right) / \mathrm{h}\left(\mathrm{t}_{\mathrm{n}}\right)$
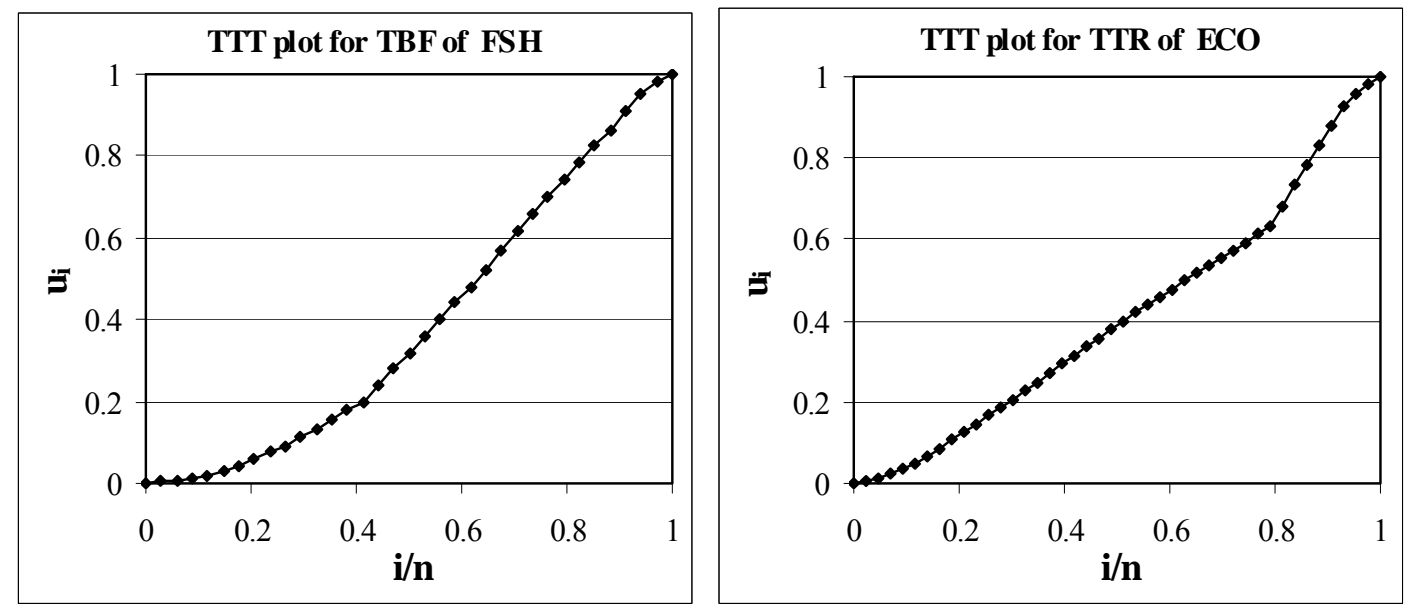

Fig. 8. TTT plots for non-idd data sets

It is observed from the Fig. 8 that the data points lie near the diagonal, which implies that Power Law process is the suitable model. The results of best-fit distributions and their estimated parameters for TBF and TTR are shown in Table $1 \&$ Table 2 , respectively 


\section{Table 1}

Best-fit distribution for TBF data sets and estimated parameters

\begin{tabular}{lllll}
\hline S1. No. & Subsystems & Best-fit distribution & Parameters & \\
\hline 1 & ECO & Weibull & $\beta=1.3$, & $\theta=2813 \mathrm{hrs}$. \\
2 & FWT & Weibull & $\beta=2.01$, & $\theta=8775 \mathrm{hrs}$. \\
3 & BWT & Lognormal & $1 / \mathrm{s}=1.797$, & $\mathrm{t}_{\text {med }}=13963 \mathrm{hrs}$. \\
4 & PLSH & Weibull & $\beta=1.6$, & $\theta=15350 \mathrm{hrs}$. \\
5 & FSH & Non iid, NHPP, Power law process & $\beta=0.84$, & $\theta=4954 \mathrm{hrs}$. \\
6 & TUR & Weibull & $\beta=2.47$, & $\theta=14818 \mathrm{hrs.}$ \\
7 & FRH & Weibull & $\beta=1.47$, & $\theta=11638 \mathrm{hrs}$. \\
8 & CON & Weibull & $\beta=1.19$, & $\theta=2778 \mathrm{hrs}$. \\
\hline
\end{tabular}

It is observed from Table 1 that all the subsystems except BWT and FSH follow weibull distribution with shape parameter $\beta>1$, which indicates increasing failure rate (IFR) due to aging process. BWT is best fitted to lognormal distribution. For these subsystems preventive maintenance is required for reducing their failure (Samanta et al., 2000). FSH follows power law process NHPP model with shape parameter $\beta<1$, is indicating a decreasing failure rate (DFR) before it reaches its useful life or steady state condition, which support the conclusion from Trend Test plot in Figure 2(c) (concave downward curve). Therefore corrective maintenance will be economical for FSH (Samanta et al., 2000).

\section{Table 2}

Best-fit distribution for TTR data sets and estimated parameters

\begin{tabular}{lllll}
\hline Sl. No. & Subsystems & Best-fit distribution & Parameters & \\
\hline 1 & ECO & Non iid, NHPP, Power law process & $\beta=0.93$, & $\theta=140 \mathrm{hrs}$. \\
2 & FWT & Lognormal & $1 / \mathrm{s}=1.33$, & $\mathrm{t}_{\text {med }}=75 \mathrm{hrs}$. \\
3 & BWT & Lognormal & $1 / \mathrm{s}=0.95$, & $\mathrm{t}_{\text {med }}=105 \mathrm{hrs}$. \\
4 & PLSH & Weibull & $\beta=1.99$, & $\theta=235 \mathrm{hrs}$. \\
5 & FSH & Weibull & $\beta=1.42$, & $\theta=158 \mathrm{hrs}$. \\
6 & TUR & Lognormal & $1 / \mathrm{s}=3.413$, & $\mathrm{t}_{\text {med }}=143 \mathrm{hrs}$. \\
7 & FRH & Lognormal & $1 / \mathrm{s}=1.818, \quad \mathrm{t}_{\text {med }}=128 \mathrm{hrs}$. \\
8 & CON & Weibull & $\beta=0.95$, & $\theta=23 \mathrm{hrs}$. \\
\hline
\end{tabular}

Table 2 shows that TTR of ECO is decreasing $(\beta<1)$, which support the concave upward curve in the Trend Test plot of ECO (figure 4(a)). CON follows constant TTR $(\beta \equiv 1)$.

\section{Reliability analysis}

The reliability of the subsystems for Weibull and Lognormal distributions of TBF data is calculated using equations (6) \& (7) respectively (Ebeling, 2008).

$$
R(t)=e^{-\left(\frac{t}{\theta}\right)^{\beta}},
$$

where, $\beta$ is Shape parameter $\& \theta$ is Scale parameter.

$$
R(t)=1-\phi\left(\frac{1}{s} \ln \frac{t}{t_{\text {med }}}\right),
$$


where, $\varnothing$ is the probability density function, $t_{m e d}$ is median time to failure $\& s$ is shape parameter. Reliabilities of the subsystems are calculated and tabulated in Table 3.

Table 3

Reliability of the Power Plant at the End of Different Time Intervals

\begin{tabular}{lllllllll}
\hline Time (hour) & ECO & FWT & BWT & PLSH & FSH & TUR & FRH & CON \\
\hline 400 & 0.924 & 0.998 & 1.0000 & 0.997 & 0.886 & 0.9999 & 0.993 & 0.9050 \\
800 & 0.823 & 0.992 & 1.0000 & 0.992 & 0.806 & 0.9993 & 0.981 & 0.7965 \\
1200 & 0.719 & 0.982 & 1.0000 & 0.984 & 0.738 & 0.9980 & 0.965 & 0.6917 \\
1600 & 0.619 & 0.968 & 1.0000 & 0.975 & 0.679 & 0.9960 & 0.947 & 0.5952 \\
2000 & 0.526 & 0.950 & 0.9997 & 0.964 & 0.627 & 0.9930 & 0.928 & 0.5084 \\
3000 & 0.337 & 0.891 & 0.9970 & 0.931 & 0.519 & 0.9810 & 0.873 & 0.3343 \\
4000 & 0.206 & 0.814 & 0.9874 & 0.893 & 0.434 & 0.9616 & 0.812 & 0.2138 \\
5000 & 0.121 & 0.724 & 0.9671 & 0.850 & 0.365 & 0.9343 & 0.749 & 0.1338 \\
7000 & 0.038 & 0.530 & 0.8925 & 0.756 & 0.263 & 0.8553 & 0.623 & 0.0497 \\
10000 & 0.006 & 0.272 & 0.7258 & 0.607 & 0.165 & 0.6853 & 0.449 & 0.0102 \\
13000 & & 0.110 & 0.5517 & 0.466 & 0.106 & 0.4851 & 0.308 & 0.0019 \\
16000 & & 0.035 & 0.4013 & 0.343 & 0.069 & 0.2984 & 0.203 & \\
20000 & & 0.005 & 0.2579 & 0.215 & 0.040 & 0.1224 & 0.109 & \\
25000 & & & 0.1469 & 0.110 & 0.020 & 0.0260 & 0.046 & 0.018 \\
30000 & & & 0.0840 & 0.052 & 0.011 & 0.0032 & 0.006 & \\
35000 & & & 0.0495 & 0.022 & 0.006 & & & \\
\hline 40000 & & 0.0294 & 0.009 & & & \\
\hline
\end{tabular}

From Table 3, it is seen that ECO, CON and FWT are more critical with respect to reliability point of view than the other subsystems as their reliability becomes zero within 10000, 13000 and 20000 hours respectively, before other subsystems. Therefore subsequent steps are to be taken for improvement of their reliability before other subsystems for maximum improvement in the availability of the power plant.

\section{Reliability-based Preventive Maintenance Interval (PMI) estimation}

PM activity is carried out at predetermined time in order to reduce the probability of failure of any repairable system (Ghasrchami et al., 1998). The preventive maintenance cost increases when the inspection and maintenance interval is shortened by maintenance at the higher reliability level. On the other hand, risk or loss caused by failure will increase when the inspection and maintenance interval is lengthened (Okumura and Okino, 2003; Rajasankar et al., 2003). J. Barabady (2005) has suggested the setting of Preventive Maintenance Intervals (PMI) of mining equipments initially at $75 \%$ reliability level excluding maintenance cost. Here we also suggested the setting of PMIs of the subsystems initially at $75 \%$ reliability. PMIs may be set at higher reliability level considering maintenance cost, and other influencing factors which are not considered here. The PMIs for the subsystems except FSH $(\beta<1)$ at different reliability levels are calculated and tabulated in Table 4.

Table 4

Reliability-based Preventive Maintenance time intervals

\begin{tabular}{llll}
\hline Subsystems & \multicolumn{2}{l}{ Reliability-based Preventive Maintenance Intervals (hours.) } \\
\cline { 2 - 4 } & 0.90 & 0.80 & 0.75 \\
\hline ECO & 495 & 880 & 1075 \\
FWT & 2850 & 4150 & 4720 \\
BWT & 6810 & 8750 & 9570 \\
PLSH & 3900 & 6000 & 7100 \\
TUR & 5950 & 8080 & 8950 \\
FRH & 2500 & 4195 & 4980 \\
CON & 415 & 785 & 970 \\
\hline
\end{tabular}




\section{Availability analysis}

Operational Availability $\left(\mathrm{A}_{\mathrm{op}}\right)$ of the subsystems have been estimated following equation (8) and subsequently tabulated in Table 5 .

On implementing PM strategy in the plant, the availability of the subsystems might be improved as

$$
A_{o p}=\frac{M T B F}{M T B F+M D T},
$$

shown in the same Table 5, where MDT is Mean Down Time.

Table 5

Comparison of Availability of the subsystems before and after Preventive Maintenance

\begin{tabular}{lllllll}
\hline Subsystems & $\begin{array}{l}\text { MTBF (hrs.) } \\
\text { before PM }\end{array}$ & $\begin{array}{l}\text { MTBF (hrs.) } \\
\text { after PM }\end{array}$ & $\begin{array}{l}\text { MDT (hrs.) } \\
\text { before PM }\end{array}$ & $\begin{array}{l}\text { MDT (hrs.) } \\
\text { after PM }\end{array}$ & $\begin{array}{l}\mathrm{A}_{\text {op }} \\
\text { before PM }\end{array}$ & $\begin{array}{l}\mathrm{A}_{\text {op }} \\
\text { after PM }\end{array}$ \\
\hline ECO & 2620 & 9887 & 233 & 65 & 0.9183 & 0.994 \\
FWT & 7774 & 20982 & 572 & 488 & 0.9314 & 0.977 \\
BWT & 15298 & 95324 & 945 & 49 & 0.9418 & 0.9995 \\
PLSH & 13753 & 48055 & 718 & 182 & 0.9504 & 0.996 \\
FSH & 5425 & & 422 & & 0.9279 & \\
TUR & 12175 & 31683 & 819 & 804 & 0.9370 & 0.9753 \\
FRH & 10533 & 64861 & 686 & 112 & 0.9388 & 0.998 \\
CON & 2466 & 5780 & 60 & 55 & 0.9762 & 0.9906 \\
\hline
\end{tabular}

From Table 5, it is seen that if preventive maintenance were performed in the suggested intervals then the availability gets improved.

\section{Maintainability analysis}

The maintainability (M) for all subsystems at the end of different mission times ( $\mathrm{t}$ ) have been estimated following equations (9) \& (10) for Weibull or Lognormal distribution (Ebeling, 2008) of TTR data sets respectively and is tabulated in Table 6.

$$
\begin{aligned}
& M(t)=1-e^{-\left(\frac{t}{\theta}\right)^{\beta}}, \\
& M(t)=\phi\left(\frac{1}{s} \ln \frac{t}{t_{\text {med }}}\right) .
\end{aligned}
$$

\section{Table 6}

Maintainability of the Power Plant at the End of Different Time Intervals

\begin{tabular}{lllllllll}
\hline Time (hour) & ECO & FWT & BWT & PLSH & FSH & TUR & FRH & CON \\
\hline 10 & 0.082 & 0.003 & 0.012 & 0.002 & 0.020 & 0.000 & 0.000 & 0.326 \\
20 & 0.150 & 0.039 & 0.058 & 0.007 & 0.052 & 0.000 & 0.000 & 0.533 \\
50 & 0.317 & 0.295 & 0.242 & 0.045 & 0.178 & 0.000 & 0.045 & 0.838 \\
100 & 0.517 & 0.648 & 0.484 & 0.167 & 0.407 & 0.115 & 0.330 & 0.970 \\
150 & 0.654 & 0.821 & 0.633 & 0.335 & 0.606 & 0.567 & 0.614 & 0.994 \\
200 & 0.750 & 0.903 & 0.729 & 0.515 & 0.753 & 0.875 & 0.788 & 0.999 \\
300 & 0.868 & 0.967 & 0.840 & 0.802 & 0.917 & 0.994 & 0.938 & 1.000 \\
400 & 0.929 & 0.986 & 0.898 & 0.944 & 0.976 & 0.999 & 0.980 & 1.000 \\
500 & 0.961 & 1.000 & 0.932 & 1.000 & 1.000 & 1.000 & 1.000 & 1.000 \\
\hline
\end{tabular}


Table 6 shows that maintainability of ECO and BWT are less than 1 even after 500 hours i.e. they need more time to repair than other subsystems. Hence, their repair times need to be reduced first by proper maintenance procedure and maintenance resource allocation at right time for maximum improvement in the availability.

\section{Conclusions}

All the TBF/TTR data sets of the Unit-2 are found to be independent and identically distributed except TBF data of FSH and TTR data of ECO. All the subsystems except BWT and FSH follow weibull distribution with shape parameter $\beta>1$, which indicates IFR due to aging process. BWT is best fitted to lognormal distribution. For these subsystems preventive maintenance is required for reducing their failures. Although ECO and FSH had more frequency of failure than the other subsystems, FSH followed DFR $(\beta<1)$ i.e. it is in the burn-in period. Hence corrective maintenance will be economical for FSH. PRH had only one failure and PSH had no failure during the study period. ECO and FWT are more critical with respect to reliability point of view than the other subsystems. Therefore, more attention is to be given to these subsystems regarding preventive maintenance for reducing their failures. Again ECO and BWT are found to be critical from maintainability point of view. Therefore, their repair times are to be reduced by adopting proper maintenance procedure. Further timely maintenance resource allocation may be provided in order to improve availability.

In the Unit-1, it was observed that, ECO \& PSH had more frequency of failure than that of the other subsystems. FSH having DFR $(\beta<1)$ needed corrective maintenance. ECO and PSH were more critical with respect to reliability, whereas PSH and FWT were critical with respect to maintainability.

Therefore the study shows that FSH follows DFR in both the plants. Further, it has been observed that the PSH had no failure in the Unit-2 whereas in Unit-1 it had more frequency of failure during the study period. Different subsystems are critical in the two different plants from the same power station, however ECO is found to be the most critical subsystem from all points of view in both the plants.

If preventive maintenance is performed at least at $75 \%$ reliability level without considering maintenance cost and other factors of the subsystems, still their reliability will improve which in turn will enhance the availability of the power plants.

\section{References}

Arora, N. \& Kumar, D. (1993). Maintenance planning and management of coal crushing system in the thermal power plant. Proceedings of the ORSI 26th Convocation. Bhubaneshwar, India.

Arora, N., Kumar, D. \& Yadav, V. (1995). Reliability analysis and maintenance planning of coal conveyor system in a thermal power plant. Proceedings of AIEPIT, Allahabad, India, 13-18.

Arora, N. \& Kumar, D. (1997). Availability analysis of Steam and Power Generation Systems in the Thermal Power Plant. Microelectronics Reliability, 37 (5), 795-799.

Arora, N. \& Kumar, D. (1997). Stochastic analysis and maintenance planning of the ash handling system in the thermal power plant. Microelectronics and Reliability, 37 (5), 819-824.

Adhikary, D.D., Bose, G.K., Mitra, S. and Bose, D. (2010). Reliability, Maintainability \& Availability analysis of a coal fired power plant in eastern region of India, Proceedings of the 2nd International Conference on Production and Industrial Engineering (CPIE 2010), NIT, Jalandhar, India, 1505-1513. 
Behera, S.K. \& Dash, A.P. (2010). Performance Analysis of Coal fired Power Plants in India. Proceedings of the 2010 International Conference on Industrial Engineering and Operations Management, Dhaka, Bangladesh.

Barabady, J. (2005). Reliability and maintainability analysis of crushing plants in Jajarm bauxite mine of Iran. Proceedings of the Annual Reliability and Maintainability Symposium, USA, 2005, 109-115.

Barabady, J. \& Kumar, U. (2008). Reliability analysis of mining equipment: a case study of a crushing plant at Jajram Bauxite Mine in Iran. Reliability Engineering and System Safety, 93 (4), 647-653

Ebeling, C. (2008). An Introduction to Reliability and Maintainability Engineering, 10th ed., Tata McGraw-Hill, New Delhi, India.

Ghasrchami, K. B., Price, J.W.H. \& Mathew, J. (1998). Optimum inspection frequency for manufacturing systems. International Journal of Quality \& Reliability Management, 15 (3), 250258.

Kumar, U. \& Kelefsjö, B. (1992). Reliability analysis of hydraulic system of LHD machine using the power low process model. Reliability Engineering and System Safety, 35, 217-224.

Kaushik, S. \& Singh, I.P.(1994). Reliability analysis of the feed water system in a thermal power plant. Microelectronics Reliability, 34 (4), 757-759.

Okumura, S. \& Okino, N. (2003). An inspection policy for a stochastically failing single-unit system. Procedings of Eco Design-2003: Third International Symposium on Environmentally Conscious Design and Inverse Manufacturing, Tokyo, Japan, 137-140.

Purbolaksono, J., Ahmad, J., Khinani, A., Ali, A.A., \& Rashid, A.Z. (2010). Failure case studies of SA213-T22 steel tubes of boiler through computer simulations. Journal of Loss Prevention in the Process Industries, 23 (1), 98-105.

Rahman, M.M., Purbolaksono, J. \& Ahmad, J. (2010). Root cause failure analysis of a division wall superheater tube of a coal-fired power station. Engineering Failure Analysis, 17 (6), 1490-1494.

Rigdon, S.E. \& Basu, A.P. (2000). Statistical Methods for the Reliability of Repairable Systems, John Wiley \& Sons, Inc, USA.

Rajasankar, J., Iyer, N.R. \& Appa Rao, T.V.S.R. (2003). Structural integrity assessment of offshore tubular joints based on reliability analysis. International Journal of Fatigue, 25, 609-619.

Shu, L., Lingen, C., Jin,J., Yu, J., Sun, F., \& Wu.C. (2005). Functional reliability simulation for a power- station's steam-turbine. Applied Energy, 80(1), 61-66.

Samanta, B., Sarkar, B., \& Mukherjee, S.K. (2000). Reliability, Availability \& Maintainability (RAM) of heavy earth moving machinery in an open cast mine. Minetech, 21 (5), 15-19.

Woo, Thomas G. (1980). Reliability analysis of a fluidized-bed boiler for a coal-fueled power plant. IEEE Transactions on Reliability, 29 (5), 422-424. 